\title{
Pavel Florensky's Theory of Religious Antinomies
}

\author{
Paweł Rojek(0)
}

\begin{abstract}
Pavel Florensky (1882-1937), a Russian theologian, philosopher, and mathematician, argued that the religious discourse is essentially contradictory and put forward the idea of the logical theory of antinomies. Recently his views raised interesting discussions among logicians who consider him a forerunner of many non-classical logics. In this paper I discuss four interpretations of Florensky's views: paraconsistent, L-contradictory, non-monotonic and rhetorical. In conclusion I argue for the integral interpretation which unites these four approaches.
\end{abstract}

Mathematics Subject Classification. Primary 03A05; Secondary 03B65, 03B42, 03B53.

Keywords. Florensky, Logic of religion, Antinomy, Contradiction, Paraconsistency, L-inconsistency, Non-monotonic logic, Rhetoric.

\section{Introduction}

Pavel Florensky (1882-1937) was the first man who attempted to combine Orthodox theology with modern logic. ${ }^{1}$ In 1914 he published the famous book The Pillar and the Ground of Truth [18], in which he aimed to express the truth of Orthodoxy by various means of his contemporary culture, including

\footnotetext{
1 This paper is an extended version of my chapter [37]; I give more comprehensive discussion of Florensky's logic in my forthcoming book [39].

The first draft of this paper was presented at The Second World Congress on Logic and Religion, Warsaw, June 19, 2017.

I am grateful to participants of the Congress for the helpful discussion, and to Viacheslav Moiseev, Teresa Obolevitch, Igor' Priadko, Tat'iana Rezvykh, Christoph Schneider and two anonymous reviewers for their comments. I also thank to Ewelina Jaskiewicz and Katarzyna Popowicz, who helped me in editing the text. The publication has been generously supported by a Grant from the National Science Center, Poland, No. 2014/15/B/HS1/01620.
} 
art, literature, philosophy, science, and, notably, mathematical logic. Regarding logic, Florensky argued that the ultimate religious truth goes beyond the available formal categories, and Christianity is essentially antinomical. As he believed, the Holy Scripture and the Christian dogmatics consist of true, yet contradictory, statements, and these contradictions should not be forcibly resolved, but rather willingly accepted as a proper expression of the religious truth. To him, the highest summit and the deepest source of antinomies was the dogma of the Holy Trinity. Florensky, however, not only pointed out that difference but also tried to sketch the idea of a new logic of antinomy which could deal with religious contradictions.

Florensky's book initiated a major debate among Russian theologian$\mathrm{s}$ and religious philosophers, first in Russia, and then, after the communist revolution, also abroad, among exiled scholars. It has been reviewed by such eminent figures as Nicholas Berdyaev, Evgeny Trubetskoy, Vasily Rozanov, Georges Florovsky and many others (see [23]). Sergei Bulgakov and Alexei Losev directly took and developed many Florensky's ideas. However, neither of these authors was a logician and hence they could hardly understand, and even less discuss, the logical aspects of Florensky's work. Only recently, at the beginning of the new century, mostly among Russian logicians, the logical ideas of Florensky raised serious discussions. Most commentators appreciate his professional mathematical background. As Viacheslav Moiseev, a contemporary Russian philosopher, put it, Florensky was "a philosopher and a priest, a philologist and a mathematician, a poet and an engineer - and all this was combined in one person which mastered each of these activities fully professionally" [28, p. 116]. Florensky is supposed to receive an "excellent mathematical education" [8, p. 38], to be "quite familiar with his contemporary symbolic logic" [42, p. 172], and his Pillar and the Ground of Truth is assessed as "a work of great logical, mathematical, and philosophical rigor" [19, p. 175]. It is often suggested that Florensky anticipated many logical ideas developed only long after his death, such as paraconsistent [7, p. 20], [8, pp. 31, 62], [33], [35, p. 98], [42, pp. 167, 176] non-monotonic [42, p. 167], many-valued [8, p. 68], and probabilistic logics [8, p. 70]. In short, Florensky is usually considered a genius and "the adequate and deeper understanding of the greatness of that personage is a matter of future" [7, p. 21].

There is, however, also the other side of Florensky's logic. First of all, it is surprising that suspiciously many of logical formulas in his works prima facie make no sense. This is true not only about his own logical symbols, which often lack a determine meaning, but also about his attempts of formalization in standard predicate language. Perhaps some cases are simple misprints; others might be the result of the ambiguity of logical connectives. Nevertheless, too many formulas seems to be plainly wrong. What is worse, his own clarifications are often not helpful at all. As it was put by Irina Gerasimova, "in Florensky's texts the formal formulas in the exact language of logic do not agree with his translation of these formulas and explanations given in natural (Russian) language" [20, p. 79]. In some cases the explanations given by Florensky directly contradict the symbolic formulas (see for instance [15, pp. 
88, 90]; cf. [38, p. 138]). Not surprisingly, some commentators simply reject Florensky's logical views as meaningless. For instance, Viacheslav Bocharov, a famous Soviet logician, took his ideas as plain "abracadabra in Hegel's spirit" [9, pp. 122-123]. He was also disgusted by his colleagues, Boris Biriukov and Igor' Priadko, who believed that they may contain profound truths [9, p. 124]. In the face of such problems, some commentators, such as Gerasimova, proposed to read logical formulas not literally, as expressing some logical content, but rather metaphorically, as poetic or rhetorical devices. The problem with Florensky is however even more wider. Andrei Bronnikov even opposes calling him a scientist or mathematician [10, pp. 91-92]. Though Florensky was familiar with scientific and mathematical concepts and was able to use them in his works, his true goal was never the scientific explanation of the world. What he wanted to do was to create a "syncretic meta-language of theology, science, and art" [10, p. 92]. According to Bronnikov, who himself is both a scientist and a writer, Florensky's most important mathematical work, Imaginaries in Geometry, though written in a form of scientific treatise, was in fact a kind of sophisticated poetry. "We cannot", says Bronnikov, "call Florensky a scientist, but we can call him a poet of the language of science" [10, p. 113].

In this paper I am going to present, systematize, and summarize the recent discussion on the Florensky's logical ideas. I adopt here a moderate view. I believe that Florensky aimed to provide a real logical analysis, even though in many cases he simply failed to do it. Logical mistakes and oddities should not however veil his deep insights and intuitions. What we need now is a careful and sympathetic interpretation and development of his ideas. I will limit myself only to the debate raised by his Pillar and the Ground of Truth and only to his idea of the logic of antinomy in application to religious discourse. Firstly, I sketch Florensky's views on antinomies as they stand in his fundamental work (Sect. 2). Next, I propose a simple classification of logical interpretations of Florensky's views presented by various commentators and briefly review the paraconsistent, L-contradictory, non-monotonic and rhetorical readings of his logical theory of antonimy (Sect. 3). Finally, I offer a unified interpretation combining some elements from the previous ones (Sect. 4). I believe that Florensky's views might be interpreted and developed into a consistent and insightful theory of religious discourse, finding indeed, as Christoph Schneider suggested [41], a third way between the rational ontotheology on the one hand, and irrational fideism on the other.

\section{Florensky's Theory of Religious Antinomy}

Pavel Florensky's expressed his view on antinomies most of all in the two passages in the The Pillar and the Ground of Truth: in Letter Six, directly devoted to the problem of contradiction, and in one of the additional chapters, in which he analyzed a logical paradox posed by Lewis Carroll [18, pp. 106123 and 355-358]. Letter Six is more general and philosophical, whereas the appendix on Carroll's problem is more specific and logical. For now, I shall 
merely present Florensky's claims without comments and clarifications, leaving it over to the next sections.

\subsection{The General Idea of Antinomy}

Florensky believed that the ultimate truth is essentially antinomic. This is definitely the most striking and - for many - the most inspiring logical idea of his Pillar and Ground of Truth. In Letter Six he states clearly:

For rationality [rassudok], truth is contradiction, and this contradiction becomes explicit as soon as truth acquires a verbal formulation ... The thesis and the antithesis together form the expression of truth. In other words, truth is an antinomy, and it cannot fail to be such [18, p. 109].

This is a perfectly clear expression of radical dialetheism [32]. Florensky openly allowed for some contradictory sentences to be both true. He was fully aware that by doing this, he undermined the foundation of rational thinking, namely the principle of noncontradiction. His personal attack on this principle was as passionate as its famous defense by Aristotle in Metaphysics IV. He urged:

We must not, we dare not, cover contradiction over with the paste of our philosophemes! Let contradiction remain as profound as it is ... The impotent exertion of human rationality to reconcile contradictions should have been repulsed long ago by a bold acceptance of contradictoriness [18, p. 116].

It seems therefore, that Florensky might be seen as an early proponent of the non-classical logic, based on the rejection of the principle of noncontradiction.

Florensky not only put forward the idea of dialetheism but also attempted to sketch a kind of formal theory of antinomy ${ }^{2}$. First of all, he proposed the following "symbolic definition of the antinomy":

$$
\mathrm{P}=(\mathrm{p} \wedge \neg \mathrm{p}) \wedge \mathrm{V} \text {. }
$$

An antinomy $\mathrm{P}$ is a conjunction of thesis and antithesis accompanied by a sign "V" meaning "truth" (veritas). The addition of that symbol was intended to distinguish the necessary philosophical antinomies, rooted in the nature of things, and mere contingent formal contradictions, resulting from simple mistakes. As Florensky clarified,

For pure logic, $\mathrm{V}$ in the definition of $\mathrm{P}$ is only ... an indication of the relation that is required toward it; $\mathrm{V}$ is a finger pointing to the sky in the presence of $\mathrm{P}$... In the rational sphere only authority is that finger which indicates the truthfulness of $\mathrm{P}[18, \mathrm{p} .113]$.

\footnotetext{
${ }^{2}$ Florensky adopted the old-fashioned symbolism of Peano and Russell; here and henceforth, I translate it into a more accessible notation. Note that Florensky accepted two ways of reading of logical connectives. For instance, he claimed that sign " $\supset$ " might be read either as propositional "implication" or as set-theoretical "inclusion" [16, p. 600]; unfortunately this important clarification has been omitted in English translation, see [18, p. 425, translator's note]. Here I follow solely the first, more standard reading. For an attempt of interpretation the second reading see [6, pp. 165-166].
} 
The special symbol "V" is necessary, since the logical structure of the true deep antinomies and mere apparent contradictions are exactly the same. In a deeper sense, this symbol "raises the antinomy above the plane of rationality" $[18$, p. 113], and "represents ... the spiritual unity, the supersensuous reality of antinomy", which is "experienced and perceived directly" in "the Holy Spirit" [18, pp. 113-114].

I leave aside here the question of philosophical sources of Florensky's dialetheism. There have been many authors who had expressed similar intuitions before. Florensky himself admitted being generally inspired first of all by Immanuel Kant.

In the history of the shallow and boring thought of "modern philosophy", Kant had the boldness to utter the great word "antinomy", which violated the decorum of the apparent unity. For this alone he would have merited eternal glory [18, p. 117] (see also [14] and [18, p. 347]).

Though the term "antinomy" is quite a recent invention, the very idea of self-contradictoriness of rational thinking is as old as philosophy. Florensky traced it down in Heraclitus, Plato, Nicholas of Cusa, and, more recently, in Hegel, Fichte and Schelling [18, pp. 114-118]. He claimed to have found antinomic intuitions also in contemporary linguistics, mathematics, philosophy and theology [18, p. 488].

There are also some interesting historical parallels of Florensky's view which I cannot investigate here. Florensky worked on his logical theory of antinomy for many years and published his final results in 1913. In 1910 a Polish logician, Jan Łukasiewicz, published a book on the principle of noncontradiction in Aristotle in which he undermined the special status of this principle. At the same time, in Russia, Nikolai Vasiliev started to publish his papers on imaginary logics, in which he openly rejected the principle of noncontradiction (see $[25,46,47]$, cf. [32, pp. 146-147]). Though they lived at the same time, Florensky, Łukasiewicz and Vasiliev evidently did not know each other, and hence there is no question of mutual influence. ${ }^{3}$

It is unclear what the intended scope of Florensky's claim was. In some places he suggested that every truth is in fact antinomic. "Here, on earth, there are contradictions in everything" [18, p. 117]. When it comes to details, however, he spoke mainly on religious truths, expressed in Holy Scripture, dogmatics or liturgy. I shall focus here only on these religious contradictions. It seems that his theory of antinomy is most convincing as a theory of religious language, which indeed prima facie contains contradictory statements. His attempts to prove the general thesis that all truths are antinomic seem to be very doubtful.

Florensky propounded three general arguments for the contradictory nature of truth. The first one might be called epistemological. Florensky noticed that only the antinomic statements are in fact not refutable and hence indubitable.

\footnotetext{
${ }^{3}$ For the relation between ideas of Florensky and Vasiliev see [1, pp. 114-132], [8] and [35, p. 85]; for the blurred relation between ideas of Łukasiewicz and Vasiliev see [49].
} 
A rational formula can be true if and only if it foresees, so to speak, all objections to itself, and answers them. But to foresee all objections, it is necessary to take not them concretely but their limit. It follows that truth is a judgment that also contains the limit of all its refutations, or (in other words) that truth is a self-contradictory judgment [18, p. 109]. ${ }^{4}$

Therefore, according to Florensky, there is no way to refute antinomies, for they contain both thesis and antithesis. And that is what makes them the highest form of knowledge. Second, Florensky made an attempt to formulate a general, purely logical "proof of antinomy". He recalled two versions of the valid reductio ad absurdum principle:

$$
\begin{aligned}
& (\neg \mathrm{p} \rightarrow \mathrm{p}) \rightarrow \mathrm{p}, \\
& (\mathrm{p} \rightarrow \neg \mathrm{p}) \rightarrow \neg \mathrm{p} .
\end{aligned}
$$

Florensky easily proved (2) by the definition of implication and the law of double negation, and then obtained (3) by the substitution of $\mathrm{p}$ in (2) by $\neg \mathrm{p}$ [18, p. 112]. Both formulas (2) and (3) are plain tautologies of classical logic. Surprisingly enough, Florovsky claimed that the deduction of (2) and (3) somehow forms a logical proof of antinomy. He concluded:

So that one has proved not only p (2) but also not-p (3). Thus, we have obtained two equally indubitable proofs which make up the antinomy $\mathrm{P}$... Using the methods of pure logic we have shown the possibility of antinomy in the strictest sense of the word [18, p. 113] [I have changed the numerals in brackets accordingly].

Strictly speaking, this proof, if it was sound, would prove not merely the possibility, but also the necessity of antinomy.

After that, Florensky proposed a reformulation of his own definition of antinomy (1). "For greater clarity", as he wrote, he joined the antecedents of (2) and (3), and arrived at the following formula:

$$
\mathrm{P}=((\neg \mathrm{p} \rightarrow \mathrm{p}) \wedge(\mathrm{p} \rightarrow \neg \mathrm{p})) \rightarrow \mathrm{p} \wedge \neg \mathrm{p} \wedge \neg \Lambda .
$$

The sign " $\Lambda$ " was thought as opposition of "V" and was supposed to mean "falsity". Florensky read (4) as follows: "If antithesis entails the thesis and, at the same time, the thesis entails the antithesis, the combination of the thesis and antithesis, if it is not false, is an antinomy" [18, p. 114]. The third, perhaps most serious, argument is of theological nature. Florensky linked logical antinomies with the sinful condition of the world in general, and human reason in particular.

From the point of view of dogmatics, antinomies are inevitable. If $\sin$ exists ... then our entire being, just like the whole world, is fragmented ... Whatever we take, we inevitably fragment the object we are considering, split it into incompatible aspects ... Antinomicalness comes from the fragmentedness of being itself, including rationality as a part of being [18, p. 118].

\footnotetext{
${ }^{4}$ Florensky repeated this argument in [17, p. 44].
} 
The fragmentation of the creation is a result of the original sin. The world itself is fragmented, and thus all knowledge of it is supposed to be contradictory. More importantly, this fragmentation concerns also the human reason being a part of the fallen world. In result, even if the reason turns to the integral divine reality, as in the case of philosophy or theology, it forms fragmented and therefore contradictory knowledge. That is why rational knowledge is inevitably antinomic.

This result leads us back to the problem of the scope of Florensky's thesis. It seems that he simply failed to justify the general claim that all truths are antinomic. The epistemological argument obviously begs the question since it presupposes dialetheism. In classical logic the contradiction is simply a mark of falsity, not of unshakable truth. If a judgment is true, it does not contain its negation, but rather its negation is false. The following logical argument is also plainly obsolete. Florensky simply proved the principle of reductio ad absurdum in two different forms. These principles are tautologies of propositional calculus and together cannot form a contradiction. Finally, the theological argument might be sound, but only for a religious discourse. Florensky gave no additional evidence for the thesis that the fragmented reality can be grasped exclusively in a way of antinomy, though he provided reasons for the contradictory character of a religious discourse. I conclude therefore, that his theory of antinomy works best not as a general theory of knowledge, but as a particular theory of the religious language.

Florensky pointed to three main sources of contradictions in religious discourse. The first one is the religious experience. As he claimed, "an object of religion, in falling from the heaven of spiritual experience into the fleshiness of rationality inevitably splits apart into aspects that exclude one another" $[18$, p. 119]. That what is spiritually experienced as an integral whole is rationally thought in contradictory judgments.

The mysteries of religion are ... inexpressible, unutterable, indescribable experiences, which cannot be put into words except in the form of contradictions, which are "yes" and "no" at the same time [18, p. 117].

Therefore "antinomies are the constituent elements of religion, if we conceive it rationally. Thesis and antithesis, as warp and woof, bind the very fabric of religious experience" [18, p. 120].

The nature of religious experience is expressed by the theological formulas. Florensky insisted that the "living religious experience" is "the sole legitimate way to gain knowledge of the dogmas" [18, p. 5]. Dogmatic formulas therefore are supposed to be essentially antinomic. This is true, for Florensky, first of all about the dogma of the Holy Trinity, which accepts one substance and three hypostases at the same time [18, p. 121], and about the dogma of two natures of Christ, which are thought to be both "unmerged and unchanging" and "indivisible and inseparable" [18, p. 121].

Finally, according to Florensky, the contradictions are ubiquitous in the Holy Scripture, which is also a kind of expression of the religious experience. He wrote: 
The Holy Scripture is full of antinomies. Not only do the judgments of different Biblical authors ... intersect antinomically, but this is even the case for the same author - not only in different writings but even in the same writing, not only in different passages but even in the same passage. Antinomies stand side by side, sometimes in a single verse [18, p. 120].

The most striking examples are the writings of St. Paul, especially the Epistle to the Romans, which Florensky called the "antinomy-charged bursting bomb against the rational mind" [18, p. 121]. Florensky closed the Sixth Letter by an impressive table displaying most striking Christian contradictions. It includes for instance the issues of predestination and free will (Rom. 9 vs. Rom 9:3010:21), causes of $\sin$ (Rom 5:12-21 vs. 1 Cor 15:50), final fate (Rom 8:19-23 vs. Rom 2:5-12), retribution (Rom 2:6-10 vs. Rom 4:4, 9:11, 11:6), nature of grace (Rom 5: 20 vs. Rom 6:1-2), faith (John 3:16-28 vs. John 6:44), and the character of the coming of the Christ (John 9:39 vs. John 12:47).

As result, according to Florensky, the whole religious discourse, based on religious experience, is supposed to be antinomic. It is seen also in liturgy and prayers. "The whole liturgy - he claimed - especially the canons and stichera, is full of ceaselessly exuberant wit of antithetic juxtapositions and antinomic affirmations" [18, p. 117]. Florensky's formal theory of antinomy was designed exactly to capture such contradictory character of religious thought.

\subsection{The Analysis of Lewis Carroll's Puzzle}

In addition to Letter Six of The Pillar and Ground of Truth, devoted to the problem of contradiction, Florensky in one of the appendixes gave an analysis of what he called "Carroll's Problem". That rather technical text, not easily accessible for philosophers and theologians not trained in formal logic, was supposed to develop and clarify the thesis formulated in the body of the book.

Lewis Carroll, an English mathematician and logician, famous as the author of Alice in Wonderland, published in Mind in 1894 a logical puzzle known as the Barbershop Paradox [12]. He introduced it as a story about two uncles passionate in logic who discuss the customs of three local barbers: Allen, Brown, and Carr. One of them is always in the shop, and Brown appears there only with Allen. The discussion results in the following two statements:

If Allen is out, then Brown is out,

If Carr is out, then, if Allen is out, then Brown is in.

Uncle Joe argues that from these premises follows that Carr is in, since the case "Allen is out" would lead to contradiction. Carroll himself believed that this conclusion was a kind of paradox and saw this as "a very real difficulty in the Theory of Hypotheticals". "I greatly hope", he wrote, "that some of the readers of Mind who take an interest in logic will assist in clearing up these curious difficulties" [12, p. 438]. Indeed, his paradox raised a considerable debate, which engaged such authors as Alfred Sidgwick, W. E. Johnson, and Irving M. Copi. 
Quite surprisingly, Florensky saw in this logical puzzle a profound expression of a crucial problem of the logic of religion. ${ }^{5}$ He urged that it is not "extraordinary and artificially concocted difficulty, which has no significance for life", but rather "evoked by a real need" [18, p. 355], which concerns the relationship between rationality and faith. That is why, according to Florensky, "for a greater understanding of the step we take when we believe in the Truth", it is useful to "solve the aforementioned logical problem in its general form" $[18$, p. 335]. First, he reconstructed the paradox in a standard propositional calculus:

$$
\begin{gathered}
\mathrm{q} \rightarrow \mathrm{r}, \\
\mathrm{p} \rightarrow(\mathrm{q} \rightarrow \neg \mathrm{r}) .
\end{gathered}
$$

The question is what follows from these two premises. Florensky briefly reviewed two competing solutions. The first one, proposed by Lewis Carroll himself, states that if $\mathrm{q} \rightarrow \mathrm{r}$ then it is impossible that $\mathrm{q} \rightarrow \neg \mathrm{r}$, therefore $\mathrm{p}$ entails a contradiction and thus should be rejected. The second one, which he (rather mistakenly) attributed to the French logician Louis Couturat, states the opposite, namely that $\neg$ q. Florensky himself claimed that the proper solution is neither $\neg$ p, nor $\neg$ q but $\mathrm{p} \rightarrow \neg \mathrm{q}$. He proved it in the following way:

$$
\begin{aligned}
\neg \mathrm{r} \rightarrow \neg \mathrm{q} & \text { contraposition of }(7), \\
\mathrm{p} \rightarrow(\neg \mathrm{q} \vee \neg \mathrm{r}) & \text { from (8) and the definition of implication, } \\
\mathrm{p} \rightarrow(\neg \mathrm{q} \vee \neg \mathrm{q}) & \text { substitution in (10) by (9), } \\
\mathrm{p} \rightarrow \neg \mathrm{q} & \text { conclusion }([18, \text { p. 356], } \\
& \text { cf. [42, pp. 173-175], [6, pp. 164-165], [7, p. 30]). }
\end{aligned}
$$

Ironically, in the Russian original text there is a typo in the conclusion, which appearently has not been noticed yet by all the editors and translators. ${ }^{6}$ Florensky believed that his conclusion somehow unites the two above mentioned competing solutions. Neither p, nor q are prima facie absurd, but they might not be true at the same time. His proof is obviously correct. The same solution of the Barbershop Paradox was given, for instance, by Bertrand Russell in his Principles of Mathematics [40, pp. 16-18]. ${ }^{7}$ That is why nowadays Carroll's puzzle is not considered as a logical paradox but rather as a mere logical mistake resulting from the early unclear understanding of the peculiarities of the logical connectives.

Florensky nevertheless believed that his solution of Carroll's problem may help us understand the relation between faith and reason. The suggestion was that the premise $\mathrm{p}$ somehow changes the logical status of the other propositions. He clarified:

\footnotetext{
${ }^{5}$ Florensky was not familiar with Carroll's paper directly. He referred to Couturat and, as Rhodes noticed, repeated his mistake in reference, see [34, p. 608].

${ }^{6}$ He put " $\mathrm{p} \cup-\mathrm{q}$ " (that is "p $\vee \neg \mathrm{q}$ ") instead of "p $\supset$-q" (that is "p $\rightarrow \neg q$ "), see [18, p. 356], cf. [16, p. 501].

${ }^{7}$ Russell deeply influenced Couturat, so he had also indirect effect on Florensky, see [34, p. $611]$.
} 
In the presence of $\mathrm{p}, \mathrm{q}$ is revoked; but in all other cases, it is in force ... The usual, everyday, ubiquitous q stops being such under special conditions, precisely under condition p [18, p. 357].

The condition $\mathrm{p}$, therefore, might be compared with faith, whereas the other propositions correspond with the rational thought. The leap of faith consists in the acceptance of p, which modifies the entire worldview. Logics, Florensky suggested, leaves room for such change.

This interesting general suggestion was developed in one of Florensky's examples of the application of the Carroll's scheme. Florensky proposed the following puzzle:

A rationalist says that contradiction of the Holy Scripture and of dogmas prove their non-divine origin, whereas a mystic affirms that in a state of spiritual illumination these contradictions precisely prove the divinity of the Holy Scripture and the dogmas. The question is, what conclusion should be drawn from these declarations? [18, pp. 357-358].

This is clearly a particular case of the general scheme discussed above. Here q is "The Scripture is contradictory", $\mathrm{r}$ is "The Scripture is not-divine", and $\mathrm{p}$ is "There is spiritual illumination". The problem might be therefore formulated as follows: (1) If the Scripture is contradictory then the Scripture is not-divine, and (2) If there is spiritual illumination then (if the Scripture is contradictory then the Scripture is divine). Florensky rejected two one-sided answers, namely, that there is no spiritual illumination $(\neg \mathrm{p})$ on one hand, and that there is no contradictions in the Scripture $(\neg q)$, on the other. The logic, he reminded, suggests merely that $\mathrm{p} \rightarrow \neg \mathrm{q}$, that is, in a state of spiritual illumination, there is no scriptural contradictions. Again, it leaves open the question whether such mystical states take place or not.

This particular example of illumination and contradictions links the consideration about Carroll's puzzle with the general problem of antinomy discussed above. The suggestion is that there are real contradictions in religion, but they might be somehow removed or accepted in a special state of mind. As Florensky put it:

That which is a contradiction, and an unquestionable contradiction, for the ratio, stops being a contradiction at the highest level, is not perceived as a contradiction, is synthesized. And, then, in a state of spiritual illumination, there are no contradictions [18, p. 358].

There are, therefore, two types of thought. For the mere rationality there are contradictions that witness against divinity. However, there is also the higher faculty of reason for which former contradictions form a higher unity.

Therefore, there is no need to try to convince a rationalist that there are no contradictions: they exist, they are unquestionable. But a rationalist must believe a mystic when the latter states that these contradictions turn out to be a higher unity in the light of the Sun that does not set, and then they precisely show that the Holy Scriptures and the dogmas are higher than fleshly rationality and, thus, could not be thought up by man; i.e. are Divine 
[18, p. 358]. This is, as Florensky points out, "the same conclusion at which we have arrived in the present text", that is in the body of the book.

\section{Logical Interpretations}

Florensky held that religion is essentially antinomic. This claim, however, seems to be ambiguous in two ways. The first question is, whether he understood logical contradiction in the literal sense. Perhaps, he was talking about some oppositions, contrasts, or dialectical tensions, which in fact are not necessarily formally inconsistent. This question is legitimate, since most of Florensky's examples, such as Christian dogmas or Holy Scripture, are prima facie not logical antinomies, but at most merely epistemological paradoxes.

The second question concerns the level of thinking where the alleged contradictions were supposed to occur. Florensky himself distinguished two kinds of thought - the lower "rationality" (rassudok) and the higher "reason" (razum) (see [18, p. 7, translator's note] and also [48]). This distinction goes back to ancient Greek philosophy (dianoia and nous), medieval scholasticism (ratio and intellectus), German idealists (Verstand and Vernunft), and Russian slavophiles (rassudok and razum). Roughly, the rationality is supposed to be discursive and conceptual, whereas reason is thought rather as an intellectual intuition immediately grasping the truth.

Now, combining the possible answers for these two questions, we arrive at four possible interpretations of Florensky's view (see Table 1). The first one holds that there are true logical antinomies, and that they are everywhere, both on the level of rationality and the reason. This way of interpretation accepts the commentators who put forward a paraconsistent interpretation of Florensky's ideas.

The second position holds that there are true contradictions but only on the level of reason, not rationality. The rational mind can always avoid antinomies, which nevertheless are necessary for the reason. Such reading of Florensky was suggested by Viacheslav Moiseev, an author of the original logical theory of L-inconsistency. Perhaps most commentators accept the opposite third interpretation, in which contradictions appear on the level of rationality, but not on the level of reason. Here fits also Evgenii Sidorenko's interpretation of Florensky's view as an early formulation of the idea of non-monotonic logics. Finally, there is an option according to which there are no true contradictions

TABLE 1. The classification of Florensky's interpretations

\begin{tabular}{lll}
\hline Type of interpretation & Rationality & Reason \\
\hline Paraconsistent & Inconsistent & Inconsistent \\
L-inconsistent & Consistent & Inconsistent \\
Non-monotonic & Inconsistent & Consistent \\
Rhetorical & Consistent & Consistent \\
\hline
\end{tabular}


in Florensky at all, neither on the level of rational, nor reasonable thought. An example of this kind of reading is rhetorical interpretation of Florensky's views on antinomies, recently proposed by Irina Gerasimova. Now I am going to present these four interpretations in some details.

\subsection{Paraconsistent Logics}

Florensky held that the truth is contradictory and therefore rejected the logical law of noncontradiction. As I indicated, that was not a unique idea among logicians of his time. Florensky shared some intuitions with Łukasiewicz or Vasiliev, which are now recognized as forerunners of the idea of paraconsistency $[2,3,5,26]$. Paraconsistent logic seems therefore to be the most natural context for the interpretation of Florensky's views.

Florensky claimed that religious truth is contradictory, but at the same time he was not willing to accept any sentences as true. This strongly suggests that he implicitly rejected the notorious principle of classical logic called the law of Duns Scotus:

$$
(\mathrm{p} \wedge \neg \mathrm{p}) \rightarrow \mathrm{q} .
$$

According to (12), a contradiction entails any propositions. As a result, any formal theory which happened to contain a contradiction, turns out to be trivial since every possible formula of its language become its thesis. The embarrassing principle (12) is, however, well founded in classical logic, and thus not so easy to remove. It follows from the disjunctive introduction and disjunctive syllogism: if $\mathrm{p}$, then for every $\mathrm{q}, \mathrm{p} \vee \mathrm{q}$, and thus if also $\neg \mathrm{p}$, then $\mathrm{q}$. The alternative logics, which do not allow such deductions, are called paraconsistent. Such formal systems, first outlined by a Eukasiewicz's student Stanisław Jaśkowski, then independently formulated by Florencio Asenjo and Newton da Costa, flourished in Brazilian School of Logic, and were finally widely popularized by Graham Priest (see [4,11,13,24], and also [31]). Nowadays it is perhaps the most established and the most developed branch of non-classical logic.

Florensky wanted to accept antinomy without accepting its classical consequences, and therefore might be seen as a forerunner of paraconsistent logic. Such suggestion has been made independently by Russian logicians, such as Boris Biriukov and Igor' Priadko [8, pp. 31, 62], [7, p. 20], Evgenii Sidorenko [42, pp. 167, 176], and American philosopher Michael Rhodes [35, p. 98], [33]. According to the latter, Florensky was "the first Orthodox philosopher to understand both the form of logical reasoning endemic to Orthodox thought as well as its paraconsistent implications" [35, p. 83]. According to this interpretation, the contradictions in Florensky are literal, not rhetorical. This was clearly expressed by Rhodes:

the Trinitarian and Christological dogmas of Orthodox thought are ... reckoned to be true, in spite of the obvious inconsistencies. They are not maintained as paradoxes ... For Florensky, the antinomy ... is robust. It is a contradiction ... This is not hyperbole; it is clarity [35, p. 95]. 
Consistency, Rhodes continues, is therefore rather a mark of heresy [35, p. 98]. The acceptance of the contradictions, however, did not lead to trivialization of his theory. Again, as Rhodes notices,

Florensky's paraconsistent logic being grounded in the Holy Trinity does not allow that "anything follows", rather it defines specific metaphysical parameters so that heresy as the emphasis of only one half of an antinomy can be avoided, implying, therefore, not that "anything follows", but that orthodoxy follows [33].

What is important here, is that contradictions are thought to be present not only on the level of rationality, but remain also on the level of reason. As Biriukov and Priadko suggest, the difference between the rationality and the reason lies simply in that the former does not allow contradictions, whereas the latter accepts it. This is, as they think, the conclusion of Florensky's analysis of the Carroll's problem. "The contradiction of reason is seen only by person in the state of spiritual enlightenment, accepting the authority of the Holy Scripture and the truths of Church. That is, the antinomy $\mathrm{P}$ is an antinomy only under the condition $\mathrm{s}: \mathrm{s} \rightarrow \mathrm{P}$ " [8, p. 59]. ${ }^{8}$ Supposedly, without spiritual enlightenment, "the antinomy P" could be seen as mere mistake which can be easily corrected. It is clear, therefore, at least, that even in the state of enlightenment, the truths of religion remains inconsistent, only the attitude to them is changed. That which was unacceptable for rationality becomes welcome for the reason. Also for Rhodes, Florensky's solution of Carroll's problem was not supposed to remove, but rather to emphasize the contradiction. According to him, Florensky wanted to accept both $\mathrm{p}$ and $\mathrm{q}$, even if - or rather because - $\mathrm{p}$ entails $\neg \mathrm{q}[34$, p. 613].

Commentators disagree as to the value of Florensky's efforts to develop a formal theory of antinomies. Biriukov and Priadko appreciate his intuition but criticize its formal expression. "Here it turns out", they wrote, "that though he mastered logical technique, he did not really think through the problem of how to combine the logical calculus with his own theological position" [8, p. 55]. This results, for instance, in the futile definition of antinomy (1). As they indicate, the sign " $\mathrm{V}$ " fails to change the contradiction into truth, since the whole formula remains false, as previously. Moreover, the final version of antinomy (4) surprisingly turns out to be true, though merely due to the paradoxical feature of the logical implication which is true when antecedent and consequent are both false [8, p. 56]. Alas, Florensky's bold proof of antinomy is also a simple "logical mistake". There is nothing antinomic in tautologies (2) and (3) [7, pp. 27-29] (see also [6, p. 168], [9, p. 123]). Nevertheless, Biriukov and Priadko are not confused by all these results. They believed that they could merely show that Florensky's intuitions were not expressible in classical logics. According to them, "the presented constructions were used by the thinker primarily to prove that the schemes of rationality are not sufficient for the concept of Orthodox truth" [7, p. 28] and therefore "most of the ideas of

\footnotetext{
${ }^{8}$ Biriukov in his earlier paper claimed that he could not find any traces of the idea of paraconsistency in Florensky's solution of the Carroll's problem, see [6, p. 169, note 4].
} 
Father Paul, concerning the formal aspects of thinking, go beyond the limits of [classical] logics" [7].

Michael Rhodes is even less critical than Biriukov and Priadko. For instance, he takes Florensky's formal "proof of antinomy" seriously. Though Rhodes sees some "logical peccadilloes" in Florensky's writings, he nevertheless believes that Florensky really proved that "both $\mathrm{p}$ and $\neg \mathrm{p}$ are derived from their opposites, making together the antinomy P, namely p and not-p" [33]. Unfortunately, instead of analyzing Florensky's proof, Rhodes merely reproduces his formulas and holds that they really undermine laws of identity, non-contradiction and excluded middle. "His proofs", claims Rhodes, "necessarily imply that these laws are antinomic" [33]. Regrettably, as I argued above, this proof is plainly wrong. Even if we agree that Florensky had some deep insights into logic, we should not lock our eyes on the grave nonsenses in his logical writings.

\subsection{The Theory of L-Contradiction}

Now I will turn to the second type of interpretation, which holds that the religious truths are essentially antinomic, but that contradictions do not in fact appear on the level of rational thinking, but only on the level of reason. Ordinary thinking cannot deal with contradictions and therefore always finds a way to avoid them. That is why rational thought reaches only the surface of reality. Its ultimate nature is revealed only in the suprarational illumination. The task of religious philosophy is to show the limitations of rationality, and to prepare for the encounter with the ultimate reality.

A logical theory roughly corresponding to this type of interpretation was formulated by Viacheslav Moiseev [27], [28, pp. 329-39], [29, pp. 28-44], [30, pp. 97-121] (cf. [36]). The fundamental idea of this theory was directly inspired by Florensky's remarks in the Sixth Letter of The Pillar and Ground of Truth. Moiseev's aim, however, is not to give an interpretation of Florensky's views. He pursues only his general idea of the "formal logical theory of antinomy", which should provide a "symbolic-logic algorithm" [18, p. 110] for the analysis of antinomies. Moiseev criticizes Florensky's own attempts to realize that program, in particular his formula (1). "Unfortunately", he writes, "the form of expression of antinomy proposed by Florensky cannot be considered as correct" [28, p. 176]. The problem is that in fact every formula can be completed by the sign "V". It was supposed to be a neutral symbol, which plays in logic a similar role as the one in the arithmetic. For every $\mathrm{p}, \mathrm{p} \wedge \mathrm{V}$, as well as for every a, a $\times 1=$ a. Florensky therefore failed to express his own insights. "It is clear", Moiseev concludes, "that the use of sign V by Florensky has a metaphorical meaning, which goes beyond the means of logistics" [28, p. 176].

Moiseev's own theory of antinomies was supposed to capture that missing meaning of the symbol "V" and thus became a "more adequate" realization of Florensky's project [28, p. 176]. Moiseev suggests that the rational mind can always find some logical tricks to avoid contradictions. Indeed, in the face of contradictory statements, we usually differentiate their subjects or predicates obtaining more specific and thus consistent propositions. In some cases, 
however, these solutions themselves pose a similar problem, which requires corresponding logical treatments. The true philosophical antinomies, for Moiseev, can be merely shifted, but never finally solved. Rational thought arrives as a result to an infinite series of successive solutions. According to Moiseev, in the case of true philosophical antinomies, that infinite series of solutions reaches at its limit the robust contradiction. Such formulas he calls L-contradictions ("L" for "limit"). The formal theory of L-contradictions is based on the concept of a sequence of formulas, inspired by the analogy between logic and topology. Such sequences might be finite or infinite and, just like in mathematics, might have their limits. L-contradiction is defined as infinite sequence of formulas with a contradiction in its limit. Such a sequence corresponds to the idea of logical antinomy. Nevertheless, the formal theory of L-contradiction is perfectly consistent (see the proof in [27, p. 10]). Therefore, it is not a kind of paraconsistent logic, but an alternative way of dealing with contradictions.

Moiseev does not intend to give an interpretation of Florensky's view, but he nevertheless notices that his own theory may help explain the crucial distinction between the rational and reasonable thought. He wrote:

The rational thought (rassudok) works through devices of formal logic ... The reason (razum) adds to the structures of rationality devices of logic of antinomy, dealing with contradictions and their solutions, distinguishing different kinds of solutions, static and dynamic, interacting in many dimensions and levels, which finds its most complete logical expression in the framework of logic of Lcontradictions [30, p. 121].

It is clear, therefore, that the rational thinking for Moiseev is free from contradictions, whereas the reason ultimately admits them. The antinomies, however, are accepted only as the limits of the infinite sequences of consistent rational formulas.

I would like to present Moiseev's methods by a simple example of Lcontradiction. Moiseev himself used his theory to analyze Russell's paradox [27, p. 15], [28, pp. 333-335], [29, pp. 28-34] and Gödel's proof [28, pp. 335-9], [29, pp. 34-44], suggesting that it also can be adapted for Kantian antinomies of pure reason. Recently he provided a detailed analysis of the "most important and most deep" antinomy of the Absolute, which "in many respects lies at the bottom of all metaphysical antinomies" [30, p. 105]. That fundamental antinomy claims that the Absolute is everything, and at the same time the Absolute is nothing. Here I would like to illustrate Moiseev's approach by an analysis of a simple version of his antinomy of the Absolute.

The absolute being is usually said to be both immanent and transcendent. God might be thought as being a part of the world and at the same time as transcending the whole reality. It seems to be a contradiction. If $\mathrm{P}$ means "is a part of the universe", and $\neg \mathrm{P}$ means "is not a part of the universe", then the antinomy of immanence and transcendence might be formulated as follows:

$$
\mathrm{P}(\mathrm{a}) \wedge \neg \mathrm{P}(\mathrm{a})
$$


Now, the rational thinking might easily resolve that contradiction. It might, for instance, differentiate the subject of the contradictory statement. We can split the subject a into two distinct subjects $\mathrm{a}_{1}$ and $\mathrm{a}_{2}$, say, the "immanent absolute" and the "transcendent absolute", to obtain a consistent formula:

$$
\mathrm{P}\left(\mathrm{a}_{1}\right) \wedge \neg \mathrm{P}\left(\mathrm{a}_{2}\right) .
$$

The immanent absolute $\mathrm{a}_{1}$ is a part of the universe, whereas the transcendent absolute $\mathrm{a}_{2}$ is not. Unfortunately, the price for this move is the relativization of the concept of the Absolute. The general concept of the Absolute forces us the go beyond all the limits. The transcendent absolute $\mathrm{a}_{2}$, on its way, still seems to be a part of a world, though it is not our initial world, but a wider one. That world also should be exceeded. This suggests that we should split not only the concept of the Absolute, but also the concepts of the world W and the property of being in the world $\mathrm{P}$. Therefore, there is a sequence of sets $\mathrm{W}_{1}, \mathrm{~W}_{2}, \mathrm{~W}_{3}, \ldots$, such that $\mathrm{W}_{\mathrm{n}} \subseteq \mathrm{W}_{\mathrm{n}+1}$ and $\mathrm{W}_{\mathrm{n}} \neq \mathrm{W}_{\mathrm{n}+1}, \mathrm{n}=1,2,3 \ldots$ and the corresponding sequence of properties $\mathrm{P}_{1}, \mathrm{P}_{2}, \mathrm{P}_{3}, \ldots$, such that $\mathrm{P}_{1}$ means "being in $\mathrm{W}_{1}$ ", $\mathrm{P}_{2}$ means "being in $\mathrm{W}_{2}$ " and so on. The absolute $\mathrm{a}_{1}$ is a part of $\mathrm{W}_{1}$ and hence has $\mathrm{P}_{1}$, and the absolute $\mathrm{a}_{2}$ is not a part of $\mathrm{W}_{1}$ and thus has $\neg \mathrm{P}_{1}$. Next, the absolute $\mathrm{a}_{2}$ is a part of $\mathrm{W}_{2}$, that is has $\mathrm{P}_{2}$, though the following absolute $\mathrm{a}_{3}$ is not a part of $\mathrm{W}_{2}$ and hence has $\neg \mathrm{P}_{2}$. In general, the relative immanent absolute $\mathrm{a}_{n}$ is a part of $\mathrm{W}_{n}$, that is has $\mathrm{P}_{n}$, whereas the relative transcendent absolute $a_{n+1}$ is not a part of $W_{n}$ and has $\neg P_{n}$ :

$$
\begin{aligned}
& \mathrm{P}_{1}\left(\mathrm{a}_{1}\right) \wedge \neg \mathrm{P}_{1}\left(\mathrm{a}_{2}\right), \\
& \mathrm{P}_{2}\left(\mathrm{a}_{2}\right) \wedge \neg \mathrm{P}_{2}\left(\mathrm{a}_{3}\right), \\
& \ldots \\
& \mathrm{Pn}\left(\mathrm{a}_{\mathrm{n}}\right) \wedge \neg \mathrm{P}_{\mathrm{n}}\left(\mathrm{a}_{\mathrm{n}+1}\right) .
\end{aligned}
$$

Now, Moiseev introduces here a concept of infinite sequences of formulas. In this case we obtain the following:

$$
\left\{\mathrm{P}_{\mathrm{n}}\left(\mathrm{a}_{\mathrm{n}}\right) \wedge \neg \mathrm{P}_{\mathrm{n}}\left(\mathrm{a}_{\mathrm{n}+1}\right)\right\}_{n=1}^{\infty}
$$

Once we have accepted the sequences of formulas, we can speak about their limits. It seems plausible that the infinite sequence of relative absolutes $\mathrm{a}_{1}, \mathrm{a}_{2}, \mathrm{a}_{3}$, ... approaches the absolute Absolute a: $\lim _{n \rightarrow \infty}\left\{\mathrm{a}_{\mathrm{n}}\right\}=$ a. Similarly, the infinite sequence of restricted $\mathrm{P}_{1}, \mathrm{P}_{2}, \mathrm{P}_{3}, \ldots$ tends to the unrestricted $\mathrm{P}$ : $\lim _{\mathrm{n} \rightarrow \infty}\left\{\mathrm{P}_{\mathrm{n}}\right\}=\mathrm{P}$. So we can analyze the formula (18) as follows:

$$
\lim _{n \rightarrow \infty}\left\{\mathrm{P}_{\mathrm{n}}\left(\mathrm{a}_{\mathrm{n}}\right) \wedge \neg \mathrm{P}_{\mathrm{n}}\left(\mathrm{a}_{\mathrm{n}+1}\right)\right\}_{n=1}^{\infty}=\mathrm{P}(\mathrm{a}) \wedge \neg \mathrm{P}(\mathrm{a}) .
$$

The limit of the infinite sequence of consistent formulas turns out to be the initial contradiction (13). In other words, we can solve each case of contradictions, but nevertheless the infinite sequence of such solutions tend to the robust contradiction in its limit case. It is, therefore, an example of "L-contradiction". This particular form, according to Moiseev, is characteristic for the true philosophical antinomies. 


\subsection{Non-monotonic Logics}

Now I will turn to the third type of interpretation of Florensky's view. It holds that there are true contradictions in religious discourse, but that they occur only for lower rationality, not for the higher transformed reason. It is, therefore, a direct opposition of the previous reading. The general idea behind it is that rational thought cannot grasp religious truth without contradiction, whereas the higher reason is able to see a higher unity of supposedly contradictory statements. The antinomies of rational thought may thus somehow be solved by divine illumination. I will try to show that the difference between the rationality and the reason might be explained in the terms of additional premises implicitly denied by the rationality and explicitly accepted by the reason. This kind of interpretation was first proposed by a Russian logician Evgenii Sidorenko [42]. He is one of that authors who believes that Florensky's ideas in many aspects preceded the development of contemporary logic. In particular, as he says, "Florensky put forward a number of ideas, which were made explicit in our times in the systems of non-monotonic ... logics" [42, p. 167]. To reveal this, Sidorenko provides a careful analysis of Florensky's discussion on Carroll's problem.

Sidorenko suggests that Florensky's main concern in his discussion of the Barbershop Paradox was the idea that some of our natural conclusions might be withdrawn in the face of certain supernatural circumstances. This might be thought, as Sidorenko argues, as an expression of the fundamental intuition of non-monotonic logics. Classical logic is based on the relation of logical consequence $\mathrm{Cn}$ which satisfies conditions of reflexivity, idempotency, and monotonicity:

$$
\begin{gathered}
X \subseteq \operatorname{Cn}(X), \\
\operatorname{Cn}(X)=\mathrm{C}(\mathrm{C}(X)), \\
X \subseteq Y \rightarrow \operatorname{Cn}(X) \subseteq \operatorname{Cn}(Y) .
\end{gathered}
$$

The last principle states that any extension of a set of premises preserves the possibility of inferring the same conclusions as from the previous set. Nonmonotonic logics rejects that clause and accept the weakened relation of logical consequence $\mathrm{C}$. On the ground of non-monotonic logics the extension of the set of premises may lead to rejection of the previous conclusions, or even to acceptance of their negations. That is, when $\alpha \in \mathrm{C}(\mathrm{X})$ then it is possible that for some set of additional premises $\mathrm{Y}$ holds that $\alpha \notin \mathrm{C}(\mathrm{X} \cup \mathrm{Y})$, or even $\neg \alpha \in \mathrm{C}(\mathrm{X} \cup \mathrm{Y})$. The operator of consequence $\mathrm{C}$ might be also relativized to some set of implicitly or explicitly accepted premises $\mathrm{K}$ : $\mathrm{C}_{\mathrm{K}}(\mathrm{X})$. That set $\mathrm{K}$ might also contain the principles and rules of interpretation of $\mathrm{X}$, which is very important in the analysis of religious discourse $[44,45]$. It is believed that non-monotonic logics are more adequate to the real human reasoning in the conditions of restricted time, or limited access to information.

The point of Florensky's interpretation of Carroll's problem is that in the normal situation $\mathrm{q} \rightarrow \mathrm{r}$ holds, but under some special condition $\mathrm{p}$, which is supposed to be illumination of faith, it is not the case that $\mathrm{q} \rightarrow \mathrm{r}$ but rather that $\mathrm{q} \rightarrow \neg \mathrm{r}$. Note, the fact that in Florensky's reading the proposition $\mathrm{q}$ 
concerns the contradictory character of Holy Scripture, is irrelevant here. The most insightful is the role of the additional premise $\mathrm{p}$, which changes the final conclusion. This is clearly non-monotonic reasoning, which might be further analyzed with the help of the concept of default assumptions. As Sidorenko says,

He could agree that in default conditions the statement of inconsistency of the Holy Scripture (q) implies its non-divine character (r), but this implication loses its significance under the condition of spiritual illumination (p). It might be said that the implication $\mathrm{q} \rightarrow \neg \mathrm{r}$ is taken as true because it is actually true that $\neg \mathrm{p} \rightarrow$ ( $\mathrm{q}$ $\rightarrow \neg \mathrm{r}$ ), and $\neg \mathrm{p}$ is accepted by default [42, p. 176].

The hidden premise of the natural reason is therefore the lack of spiritual illumination $\neg$ p. This mysterious illumination might be understood not in psychological or spiritual terms, but simply as the addition of some extra premises replacing the implicitly assumed default conditions. The religious illumination is thus an extension of the set of the explicit premises.

Now, the problem was that Florensky tried to express that non-monotonic intuitions with the help of classical logic. On the one hand "Florensky's motives and arguments are perfectly clear from the point of view of simple informal reasoning and even from the point of view of ordinary common sense" [42, p. 177], but on the other hand "classical logic of propositions ... is simply not able to adequately take into account the reasons underlying Florensky's reasoning" [42, p. 177]. Sidorenko points out a number of grave inadequacies between Florensky's informal intentions and their logical expression. First, the characteristic of material implication undermines his efforts to present $\mathrm{p}$ as an additional premise, which transforms the conclusion. The problem is that in classical logic, an implication stays true even when false implies truth, therefore every true proposition might be preceded by any p. Florensky's additional premise $\mathrm{p}$ becomes thus in fact superfluous, since it could be inferred from any true proposition. Next, the conclusion of his whole reasoning is somewhat ambiguous. Florensky welcomed the formula $\mathrm{p} \rightarrow \neg \mathrm{q}$, which he read as "If there is a spiritual illumination, then there are no contradiction in Holy Scripture", but this conclusion is - by contraposition - equivalent to $\mathrm{q} \rightarrow \neg \mathrm{p}$, that is, "If there are contradictions in Holy Scripture, there is no spiritual illumination". The problem here is that Florensky openly admitted the presence of contradictions. Unfortunately, if there are contradictions, then there is no illumination, and, what is worse, from the implication $\mathrm{q} \rightarrow \mathrm{r}$ it follows also that the Scripture is not-divine. Finally, Florensky's conclusion fails to express his belief that in the state of illumination the contradictions in Holy Scripture prove its divine origin. If there is the state of illumination, then there are simply no contradictions in Scripture. If $\mathrm{p}$, then both $\mathrm{q} \rightarrow \mathrm{r}$ and $\mathrm{q} \rightarrow \neg \mathrm{r}$, and therefore $\neg \mathrm{q}$. The problem is that this conclusion obviously cannot support the divine character of Scripture. If $\neg \mathrm{q}$ then there is no way to get $\neg \mathrm{r}$. Florensky simply did not notice that problem. As a result, it seems that Florensky's formal reasoning is dramatically inadequate to his initial intuitions. The guilt, as Sidorenko suggests, lies on the side of the limitations of the classical logic. 
The judge, which was appointed by the author, allowed to justify the claims which he (the author) found desirable. He did not however notice that at the same time the logic, which he chose as a judge, allows also to justify many claims which, as we could seen, were in fact opposed to that which he wanted to prove [42, p. 177].

He concludes that we should reject the formalization of Florensky's reasoning in classical logic and seek a way to more adequate expressions.

Sidorenko outlines an alternative interpretation of Florensky's analysis of Carroll's problem on the ground of non-monotonic logics. Florensky's suggestion was that it usually holds that $\mathrm{q} \rightarrow \mathrm{r}$, but not in the face of the premise p. It means therefore that it is as a rule implicitly assumed that $\neg p$, and that assumption is explicitly rejected in the case p. The premises of the Barbershop Paradox should be therefore reformulated as:

$$
\begin{aligned}
& \neg \mathrm{p} \rightarrow(\mathrm{q} \rightarrow \mathrm{r}), \\
& \mathrm{p} \rightarrow(\mathrm{q} \rightarrow \neg \mathrm{r}) .
\end{aligned}
$$

Proposition p simply blocks the inference to $\mathrm{q} \rightarrow \mathrm{r}$ and implies that $\mathrm{q} \rightarrow \neg \mathrm{r}$. In this formalization there is no way to make a use of the removed antecedent $\mathrm{q} \rightarrow \mathrm{r}$. So, the inference to the misleading conclusion that $\mathrm{p} \rightarrow \neg \mathrm{q}$ is finally blocked. It turns out, as Florensky initially suggested, that in the state of spiritual illumination there are true contradictions, but now they are seen as evidences of the divine character of Holy Scripture. As a result, the logic shows that though there is no way to prove the divine character of the Scripture, there is also no way to obtain its non-divine character. The additional premises may always change the supposed charges into benefits.

In this interpretation, Florensky implicitly suggested a new solution to the Barbershop Paradox. He did neither, as Carroll himself, reject p, nor, as Couturat, reject $q$. Though he explicitly accepted $p \rightarrow \neg q$, that is $\neg(p \wedge q)$, he really wanted to say something completely opposite, namely that both $\mathrm{p}$ and $\mathrm{q}$ might be true. As Sidorenko clarifies, "The point of this is that p undermines the claim $\mathrm{q} \rightarrow \mathrm{r}$, that is, that the contradictions always implies non-divine character. And this is, as it seems, exactly the result, which Florensky wanted to reach" [42, pp. 182-183].

Going back to the Carroll's story, it might be said that only if Carr is in then, if Allen is out, then Brown is out, while if Carr is out, then, if Allen is out, then Brown is in. One cannot prove therefore that Carr is in. That is how Florensky should have solved the Carroll's problem. Unfortunately, the classical logic, which he adapted for his purposes, made impossible the adequate expression of his own insights. Non-monotonic logic seems to much better clarify his own intuitions.

\subsection{Rhetorical Turn}

Finally, I would like to look at the last possible kind of interpretation of Florensky's views, which fundamentally opposes the previous ones. According to it, there are in fact no real logical contradictions, neither on the level of rationality, nor on the level of reason. Florensky's so called antinomies are merely 
hyperboles aimed at shocking the reader and making him think in a new way. This interpretation obviously undermines all attempts to construct formal theories of antinomies.

Many readers of Florensky's work are confused by his reckless use of the concept of antinomy. Religious experience is actually sometimes reported in really contradictory terms, but are the Holy Scripture or Christian dogmatics truly antinomic? The Church Fathers, who put so much efforts into consistent exegesis of the Bible and coherent clarification of the Christian teaching, would probably be deeply disappointed by such a view. ${ }^{9}$ The inadequacy of Florensky's view is particularly striking in the case of the basic theological dogmas. He claimed emphatically that they are essentially antinomic. Nevertheless the thesis that God is one in nature and three in hypostasis is prima facie not a case of contradiction, since it obviously concerns two different aspects of the divine reality. The same is true about Christ, who is one person with two natures. Perhaps dogmatic definitions indeed involve implicit contradiction, but this should be argued, not simply assumed.

This consideration leads to the hypothesis that Florensky used the term "antinomy" in a loose and wide sense, not adequately captured by the concept of contradiction in formal logic. Robert Slesinski, one of the first Florensky's commentators in the West, wrote:

Florensky's deeply felt intuitions concerning the true nature of religious dogma notwithstanding, the requirements of conceptual clarity and terminological rigor demand that he be faulted for his poetic license and propensity for literary flourish. Specifically, we must question whether "contradiction" is the most felicitous choice of words [43, p. 147].

Slesinski points out that for Florensky "contradiction", "antinomy", and, notably, "coincidence of opposites" are interchangeable terms. He believes that from that three, the word "antinomy" is the most acceptable but only when used in an informal, not strictly logical way. In particular, "antinomy" should not imply robust contradiction. "Florensky's appeal to 'contradiction' may, indeed, more strikingly bring home his point, but it does so only at the price of a certain conceptual deception and obfuscation" [43, p. 142]. It seems to me that the term "paradox" would be even more appropriate here. Paradox is something which goes against the expectation but not necessary against the logic. The religious experience, the Holy Scripture and the Christian dogmatics might therefore be paradoxical in a broad sense, without being antinomic in the strict meaning.

Recently, Irina Gerasimova proposed a kind of rhetorical interpretation of Florensky's theory of antinomies [20]. She reminds us that Florensky was more poet, writer, and preacher than mathematician or logician. His concept of antinomy derived therefore from rhetoric rather than from logic. The contrast of the thesis and the antithesis is a well known classical device. Making

\footnotetext{
${ }^{9}$ Note, however, for instance Gregory Nazianzen's discussion of paradoxes in his Third Theological Oration [22, pp. 250-251]; cf. [21].
} 
striking comparisons, using abundant hyperbolas, highlighting contrasts, and introducing thought-provoking oppositions, Florensky was simply a faithful student of the ancient art of speaking. The point is, however, that in fact none of these rhetorical devices are adequately analyzable as formal contradiction.

More specifically, Gerasimova distinguishes three aspects of so called antinomies in Florensky's writings. Firstly, the logical (or rather epistemological) one helps to see complements and alternatives for the accepted thesis. Secondly, the communicative aspect concerns the use of antinomy in rhetoric. Thirdly, the psychological aspects reveals the role of such formulations in stimulating emotions and creative thinking. In all these cases antinomies are not thought literally as logical contradictions. As she concludes,

In most cases the logical connective "and" uniting the thesis and the antithesis represents the level of the metalanguage ... The proposition $\mathrm{p}$ combined with negation $\neg$ p changes its meaning in virtue of the change of its context. It would be more appropriate to write, for example, "p" for thesis and "q" for antithesis [20, pp. 86-87].

In other words, Florensky's basic formula for antinomy (1), which involves a true logical contradiction, turns out to be fundamentally misleading.

Gerasimova carefully analyzes Florensky's list of the alleged contradictions in the Holy Scripture form Letter Six of The Pillar and Ground of Truth [20, pp. 89-95]. The antinomy of grace, for instance, is only an apparent contradiction since Rome 5:20 describes the actual state of being, whereas Rome $6: 10$ and $6: 15$ concern the desired state. Similarly the antinomy of faith between John 3:16-18 and John 6:44 consist in fact of two complementary, not contradictory statements. Finally, the antinomy of Jesus' judgement simply describes the different moments in history: his first coming in John 12:47 and the second coming in John 9:39. In all these cases we have merely rhetorical figures, not logical contradictions. They are rather cases of complement statements concerning the different aspects of reality, describing the different stages of the one process, or addressed to different audience. As she concludes,

The opposition between the thesis and antithesis is not a formal or logical contradiction in the sense of classical logic. The figure of antinomy, which looks as logical contradiction from the outside, was supposed to produce an intense rhetorical effect and stimulate an emotional experience [20, p. 94].

If this is true, the whole project of the logical theory of antinomy seems to be a result of a misunderstanding of a rhetorical device. What we really need here is not a new logic but rather proper hermeneutics.

\section{Towards the Integral Theory of Antinomy}

It is not easy to determine what exactly his logical view on religious antinomies was. His original statements are so unclear, vague, and in many cases incoherent that they allow for many different interpretations. I briefly reviewed here four different types of analysis of Florensky. None of them were supposed to 
be comprehensive studies of his views. Most commentators take into account only selected passages from Florensky's writings; others are just inspired by his general ideas. While the paraconsistent, L-contradictory, and rhetorical interpretations focus on Florensky's idea of the theory of antinomies from Letter Six, the non-monotonic interpretation departs mainly from the discussion of Carroll's Paradox. Nevertheless, I believe that all of them, to some extent, express Florensky's views. Now I would like to sketch an integral interpretation which unites the results of all discussed approaches.

First of all, it seems clear that many, perhaps most, of Florensky's antinomies are in fact merely rhetorical devices, not true logical contradictions. Accordingly, in many cases, the rhetorical interpretation is the best reading of Florensky's claims. This strategy particularly applies to the alleged contradictions in Holy Scripture. Most of them can be, and actually were, resolved in many ways without violating the laws of classical logic. The same is true about many supposed contradictions in the description of the religious experience and Christian dogmatics. The first task in the process of interpretation of Florensky's view is therefore a thorough critique of all these alleged cases of religious antinomies.

However, in some limited cases, the issue is more complicated. It seems plausible that some religious statements might indeed be truly contradictory. Notwithstanding, the admission of contradictions is definitely not supposed to make it logically trivial. Contradictions are allowed only in isolated spheres and should not affect the rest of the system of beliefs. Paraconsistent logic is then very useful here.

Nevertheless, even such tamed antinomies in religious thinking are not the desired and the ultimate state. The contradictions appear only within natural thinking, which is not able to express the religious experience. The development of the religious system consists of making it consistent through the formulation of dogmas. The process starts with contradictions appearing in an initial conceptual scheme, and then transforms that scheme to resolve the contradictions. The dogmas might be seen as concepts and principles which make possible the adequate and consistent description of the reality of religion. Dogmas therefore are not to reproduce, but rather to reduce antinomies. This whole process might be described in the general frame of non-monotonic logic. Let $\mathrm{R}$ be a set of religious statements, such as the data of the revelation and/or the reports of the religious experience. At the first level, $\mathrm{R}$ contains some real contradictions. That is, for some $\mathrm{p}$,

$$
\mathrm{p} \wedge \neg \mathrm{p} \in \mathrm{C}(\mathrm{R}) \text {. }
$$

It is crucial here to avoid the triviality of $\mathrm{C}(\mathrm{R})$. That is why we really need to adopt a paraconsistent approach on this level. This is not the end, however. The contradictions in the religious discourse are only the beginning of the process of enhancement of natural rationality. This process might be thought simply as an enrichment of operation $\mathrm{C}$ by a set of additional premises and heuristics. Such a set, say D, is supposed to correspond to the dogmatics of religious discourse. This suggests a clear interpretation of the distinction 
between rational and reasonable thought. The concept of rationality might be identified with the natural consequence $\mathrm{C}$, whereas the concept of reason with the consequences $\mathrm{C}$ enabled with the premises $\mathrm{D}$, that is $\mathrm{C}_{\mathrm{D}}$. Hence, we obtain two supersets of the religious statements $\mathrm{R}$, closed under the operations $\mathrm{C}$ or $\mathrm{C}_{\mathrm{D}}$, that is containing solely formulas produced by the operations of natural or dogmatic consequences. The enlightenment by faith is seen here not as a spiritual change of the person, but rather as an enrichment of the accepted operation of logical consequence. Now, the point is that the contradictions which appear for $\mathrm{C}$ might not appear for $\mathrm{C}_{\mathrm{D}}$ :

$$
\mathrm{p} \wedge \neg \mathrm{p} \notin \mathrm{C}_{\mathrm{D}}(\mathrm{R}) .
$$

In other words, contradictions are really a matter of lower rationality, not of the higher reason. What is important, we need not deny here the presence of true contradictions in religious discourse. The formula (24) is still valid, though not ultimate. The religious experience is not consistently expressible in natural language, but might transform the language to a non-contradictory description of the divine reality.

Finally, it seems that also L-contradictory interpretation might help to clarify the development of dogmas. We start with an inconsistent set of $\mathrm{R}$, which might be made consistent by the addition of premises $\mathrm{D}$. There might be, however, a new revelation which could add some statements making $\mathrm{R}$ inconsistent again and therefore inducing the need of a new dogmatic modifications. It seems that this might be the historical case of, for instance, the development of judaic monotheistic theology into Christian trinitarian dogmatics. Now, this situation might suggest that in fact there is a sequence of sets $R_{1}, R_{2}, \ldots, R_{n}$, such that $R_{n} \subseteq_{R n+1}$ and $R_{n} \neq R_{n+1}, n=1,2,3, \ldots$, and the corresponding sequence $\mathrm{D}_{1}, \mathrm{D}_{2}, \ldots, \mathrm{D}_{\mathrm{n}}$, such that $\mathrm{D}_{1}$ makes $\mathrm{R}_{1}$ consistent, $\mathrm{D}_{2}$ makes $\mathrm{R}_{2}$ consistent and so on. The sequence of statements

$$
\left\{\mathrm{C}_{\mathrm{Dn}}\left(\mathrm{R}_{\mathrm{n}}\right) \text { is consistent } \wedge \mathrm{C}_{\mathrm{Dn}}\left(\mathrm{R}_{\mathrm{n}+1}\right) \text { is not consistent }\right\}_{n=1}^{\infty}
$$

would be of course L-contradictory.

But this is not a necessary move. Recall that in the case of the true Lcontradiction the solution of the problem at level $n$ produces the same problem at the level $n+1$. For instance, as we have seen, the concept of the Absolute goes beyond all possible limitations. It is not clear, however, whether it is the case with the revelation and its dogmatic expression. It might be that dogmatics on a particular level simply succeed in making the available religious discourse consistent. If that would be the case, the sequence of the statements would be consistent and finite, and thus there would be no L-contradiction in its infinite limit. The development of human thought gradually leads to a less contradictory view of divine reality.

I believe that such a complex, non-monotonic model is the best interpretation of Florensky's views. Though he boldly emphasized the antinomic character of religious discourse for rationality, he also clearly allowed for a consistent expression of the faith for illuminated reason. Natural philosophy might therefore transform into supranatural thought. And this transformation might start here, by the illumination of faith. This takes places, as Florensky 
suggested, in the minds of the saints, purified by ascesis and filled by divine grace. "In this mind, the healing of the fissures and cracks has begun; the sickness of being is being cured; the wounds of the world are being healed. For this mind itself is the healing organ of the world" [18, p. 118]. As I argued here, such a mind might be identified with the non-monotonic operation of the logical consequence, and the illumination by grace might be interpreted as the addition of a set of dogmatic premises. Suprarational thought is therefore a new consistent superset of the religious discourse closed under the operation of dogmatic consequence.

Open Access. This article is distributed under the terms of the Creative Commons Attribution 4.0 International License (http://creativecommons.org/licenses/by/4. $0 /$ ), which permits unrestricted use, distribution, and reproduction in any medium, provided you give appropriate credit to the original author(s) and the source, provide a link to the Creative Commons license, and indicate if changes were made.

Publisher's Note Springer Nature remains neutral with regard to jurisdictional claims in published maps and institutional affiliations.

\section{References}

[1] Antipenko, L.G.: PA Florenskii o logicheskom i simvolicheskom aspektakh nauchno-filosofskogo myshleniia. Kanon-Plius, Moscow (2012)

[2] Arruda, A.I.: Aspects of the historical development of paraconsistent logic. In: Priest, G., Routley, R., Norman, J. (eds.) Paraconsistent Logic: Essays on the Inconsistent, pp. 99-130. Philosophia, München (1989)

[3] Arruda, A.I.: NA Vasil'ev: a forerunner of paraconsistent logic. Philos. Nat. 21, 472-491 (1984)

[4] Asenjo, F.G.: A calculus of antinomies. Notre Dame J. Formal Logic 7, 103-105 (1966)

[5] Bazhanov, V.A.: The dawn of paraconsistency: Russia's logical thought in the turn of XX century. Manuscrito 34, 89-98 (2011)

[6] Biriukov, B.V.: Iz istorii matematicheskoi logiki v Rossii: Zadacha Kerolla v traktovke o. Pavla Florenskogo. Logicheskie issledovaniia 6, 163-169 (1999)

[7] Biriukov B.V., Priadko, I.P.: PA Florenskii: Filosofsko-logicheskie idei kak sredstvo eksplikatsii filosofsko-teologicheskikh vozzrenii. Vestnik Moskovskogo Universiteta. Seriia 7: Filosofiia 1, 20-35 (2011)

[8] Biriukov, B.V., Priadko, I.P.: Problema logicheskogo protivorechiia i Russkaia religioznaia filosofiia. Logicheskie Issledovaniia 16, 23-84 (2010)

[9] Bocharov, V.A.: Pavel Florenskii i logika. In: Sed'mye Smirnovskie chteniia. Materialy nauchnoi konferentsii, pp. 121-124. Sovremennye tetradi, Moscow (2011)

[10] Bronnikov, A.: Florensky and science. In: Obolevitch, T., Rojek, P. (eds.) Faith and Reason in Russian Thought, pp. 91-116. Copernicus Center Press, Kraków (2015)

[11] Carnielli, W.A., Coniglio, M.E. (eds.): Paraconsistent Logic: Consistency, Contradiction and Negation. Springer, Dordrecht (2016)

[12] Carroll, L.: A logical paradox. Mind 11, 436-438 (1894) 
[13] Da Costa, N.C.A.: On the theory of inconsistent formal systems. Notre Dame J. Formal Logic 15, 497-510 (1974)

[14] Florenskii, P.A.: Kosmologicheskie antinomii Kanta. S prilozheniem ekskursa ob antinomicheskoi strukture razuma. In: Sochineniia v Chetyrekh Tomakh. Vol. 2, pp. 3-33. Mysl', Moscow (1996)

[15] Florenskii, P.A.: Smysl idealizma. In: Sochineniia v Chetyrekh Tomakh, Vol. 3, Part 2, pp. 68-144. Mysl', Moscow (2000)

[16] Florenskii, P.A.: Stolp i utverzhdenie istiny. Opyt pravoslavioi teoditsei v dvenadtsati pis'makh. Put', Moscow (1914)

[17] Florensky, P.A.: PA Florenskii's Review of his work. Soviet Stud. Philos. 28/3, 40-51 (1989)

[18] Florensky, P.A.: The Pillar and Ground of the Truth: An Essay in Orthodox Theodicy in Twelve Letters. Princeton, Princeton University Press (2004)

[19] Foltz, B.: The fluttering of autumn leaves: logic, mathematics, and metaphysics in Florensky's the pillar and ground of truth. In: Schumann, A. (ed.) Logic in Orthodox Christian Thinking, pp. 174-203. Ontos, Hausenstamm (2013)

[20] Gerasimova, IA: PA Florenskii o protivorechii (logiko-metodologicheskii analiz). Logicheskie issledovaniia 18, 77-96 (2012)

[21] Gerogiorgakis, S.: The byzantine liar. History Philos Logic 30, 313-330 (2009)

[22] Gregory, N.: Faith Gives Fullness to Reasoning. The Five Theological Orations of Gregory Nazianzen. Brill, Leiden (1991)

[23] Isupov, K.G. (ed.): PA Florenskii: Pro et contra. Antologiia. Izdalel'stvo Russkoi khristianskoi gumanitarnoi akademii, Saint Petersburg (2001)

[24] Jaśkowski, S.: Propositional calculus for contradictory deductive systems. Studia Logica 24, 143-157 (1969)

[25] Łukasiewicz, J.: On the principle of contradiction in aristotle. Rev Metaphys 24, 485-509 (1971)

[26] Markin, V., Zaitsev, D. (eds.): The Logical Legacy of Nikolai Vasiliev and Modern Logic. Springer, Cham (2017)

[27] Moiseev, V.I.: About properties of L-inconsistent theories. Sorites 17, 7-16 (2006)

[28] Moiseev, V.I.: Logika vseedinstva. Per Se, Moscow (2002)

[29] Moiseev, V.I.: Matematicheskaia Logika. Voronezhskii gosudarstvennyi universitet, Voronezh (1999)

[30] Moiseev, V.I.: Chelovek i Obshchestvo: Obrazy Sinteza, vol. 1. Navigator, Moscow (2012)

[31] Perzanowski, J.: Fifty years of parainconsistent logics. Logic Logical Philos. 7, 21-24 (1999)

[32] Priest, G: Paraconsistency and Dialetheism. In: Gabbay, D.M., Woods. J. (ed.) Handbook of the History of Logic. Vol. 8: The Many Valued and Nonmonotonic Turn in Logic, pp. 129-204. North Holland, Amsterdam (2007)

[33] Rhodes, M.C.: Logical proof of antinomy: a trinitarian interpretation of the law of identity. Theandros $\mathbf{3 / 2}$ (2005) https://web.archive.org/web/ 20050621081523/ http://www.theandros.com/lawofident.html. Accessed 30 Nov 2017 
[34] Rhodes, M.C.: Note on Florensky's solution to Carroll's Barbershop paradox: reverse implication for russell? Philosophia 40, 607-616 (2012)

[35] Rhodes, M.C.: On contradiction in orthodox philosophy. In: Schumann, A. (ed.) Logic in Orthodox Christian Thinking, pp. 82-103. Ontos, Hausenstamm (2013)

[36] Rojek, P.: Antynomia Russella, twierdzenie Gödla i logika absolutnego. Semina Scientiarum 3, 101-110 (2004)

[37] Rojek, P.: Orthodoxy and logic: the case of pavel Florensky's theory of antinomy. In: Schneider, C. (ed.) Theology and Philosophy in Eastern Orthodoxy: Essays on Orthodox Christianity and Contemporary Thought, pp. 119-143. Pickwick, Eugene (2019)

[38] Rojek, P.: Sens idealizmu według Pawła Florenskiego. Logos i Ethos 27, 131-139 (2008)

[39] Rojek, P.: Theological Philosophy: Theology, Ontology, and Logic in Russian Religious Philosophy. Pickwick Publications, Eugene (forthcoming)

[40] Russell, B.: Principles of Mathematics. Allen \& Unwin, London (1903)

[41] Schneider, C.: Will the Truth not demand a Sacrifice from us? Reflections on Pavel A. Florensky's Idea of Truth as Antinomy in the Pillar and Ground of the Truth. Sobornost 34/2, 34-51 (2013)

[42] Sidorenko, E.A.: Logistika i teoditseia (Idei nemonotonnoi i paraneprotivorechivoi logiki u P. Florenskogo). In: Sidorenko, E.A. Logika. Paradoksy. Vozmozhnye miry, pp. 167-183. Editorial URSS, Moscow (2002)

[43] Slesinski, R.: Pavel Florensky: A Metaphysics of Love. St. Vladimir's Seminary Press, Crestwood (1984)

[44] Trepczyński, M.: Logika teologii objawionej w pismach Alberta Wielkiego i Tomasza z Akwinu. Roczniki Filozoficzne 61(3), 61-76 (2013)

[45] Trepczyński, M.: Non-monotonic logic and the compatibility of science and religion. Logica Universalis 13(4), 41-50 (2019)

[46] Vasil'iev, N.A.: Imaginary (non-aristotelian) logic. Axiomathes 3, 353-355 (1993)

[47] Vasil'iev, N.A.: Logic and metalogic. Axiomathes 3, 329-351 (1993)

[48] Vozniak, V.S.: P.A. Florenskii o samoutverzhdenii, rassudke i razume. Veche 27/2, 140-152 (2015)

[49] Żarnecka-Biały, E.: Noises in the History of Logic. Wydawnictwo Uniwersytetu Jagiellońskiego, Krakow (1995)

Paweł Rojek

Institute of Philosophy

Jagiellonian University

ul. Grodzka 52

30-962 Kraków

Poland

e-mail: pawel.rojek@uj.edu.pl

Received: November 30, 2017.

Accepted: August 30, 2019. 